\title{
Mitochondrial dysfunction in familial amyotrophic lateral sclerosis
}

\author{
Liesbeth Faes • Geert Callewaert
}

Published online: 10 November 2011

(C) The Author(s) 2011. This article is published with open access at Springerlink.com

\begin{abstract}
A growing body of evidence suggests that mitochondrial dysfunctions play a crucial role in the pathogenesis of various neurodegenerative disorders, including amyotrophic lateral sclerosis (ALS), a neurodegenerative disease affecting both upper and lower motor neurons. Although ALS is predominantly a sporadic disease, approximately $10 \%$ of cases are familial. The most frequent familial form is caused by mutations in the gene encoding $\mathrm{Cu} / \mathrm{Zn}$ superoxide dismutase 1 (SOD1). A dominant toxic gain of function of mutant SOD1 has been considered as the cause of the disease and mitochondria are thought to be key players in the pathogenesis. However, the exact nature of the link between mutant SOD1 and mitochondrial dysfunctions remains to be established. Here, we briefly review the evidence for mitochondrial dysfunctions in familial ALS and discuss a possible link between mutant SOD1 and mitochondrial dysfunction.
\end{abstract}

Keywords Amyotrophic lateral sclerosis .

Neurodegeneration $\cdot$ Mitochondria $\cdot$ Mutant SOD1

\section{Introduction}

Amyotrophic lateral sclerosis (ALS) is a progressive disease characterized by the loss of upper and lower motor neurons. In most ALS cases there is no clear genetic linkage (sporadic ALS) but in approximately $10 \%$ of ALS patients the disease is inherited (familial ALS). About $20 \%$ of these familial ALS cases are caused by autosomal dominant mutations in the gene

L. Faes $\cdot$ G. Callewaert $(\bowtie)$

Research Group Neurodegeneration, KULAK,

Etienne Sabbelaan 53,

8500 Kortrijk, Belgium

e-mail: Geert.Callewaert@med.kuleuven.be encoding $\mathrm{Cu} / \mathrm{Zn}$ superoxide dismutase 1 (SOD1) (Rosen et al. 1993; reviewed in Cleveland and Rothstein 2001; Pasinelli and Brown 2006; Turner and Talbot 2008). This enzyme mediates the conversion of superoxide anions, mainly generated during oxidative phosphorylation, into hydrogen peroxide, an indispensible defense mechanism against reactive oxygen species (ROS). To date, over 140 different mutations in the SOD1 gene have been identified (http:// alsod.iop.kcl.ac.uk/Als/Summary/summary.aspx). Since loss of SOD1 activity does not always result from these mutations (Borchelt et al. 1994; Bowling et al. 1995) and SOD1 knockout mice show no overt motor deficits (Reaume et al. 1996), it is now widely accepted that these mutations cause SOD1 to gain a toxic property. Several mechanisms for this toxicity have been proposed including mitochondrial dysfunctions, oxidative stress, $\mathrm{Ca}^{2+}$ dysregulation, aggregation of aberrantly processed proteins, endoplasmic reticulum (ER) stress, axonal transport disruption, glutamate excitotoxicity, apoptosis and inflammation (reviewed in Barber and Shaw 2010; Boillee et al. 2006; Duffy et al. 2011; Grosskreutz et al. 2010; Hervias et al. 2006; Manfredi and $\mathrm{Xu}$ 2005). The pathogenicity of SOD1 mutations therefore appears to reflect a combination of different mechanisms acting together or consecutively and ultimately leading to cell death. Dissecting out the relative significance of each mechanism remains challenging. Here, we briefly review mitochondrial dysfunction as a possible determining factor in the pathogenesis of familial ALS.

\section{Mitochondrial morphological abnormalities and dysfunctions in familial ALS}

Mitochondrial functions can be directly or indirectly linked to most, if not all, of the postulated causal mechanisms 
involved in ALS including dysregulation of intracellular $\mathrm{Ca}^{2+}$ homeostasis, oxidative stress, glutamate excitotoxicity, apoptosis and axonal transport disruption. Therefore, mitochondria can be considered as a convergence point in motor neuron degeneration. Mitochondrial damage has been well documented in both sporadic and familial ALS. The first evidence of mitochondrial abnormalities came from ultrastructural studies showing aggregates of mitochondria in muscles and spinal cord motor neurons (Sasaki and Iwata 1996) and increased mitochondrial volume in motor nerve terminals of ALS patients (Siklos et al. 1996). Consistent with these findings, observations of mitochondrial morphology in cell or animal models of familial ALS showed aggregated, swollen, vacuolated or fragmented mitochondria (Bendotti et al. 2001; Coussee et al. 2011; Damiano et al. 2006; Jaarsma et al. 2001; Jung et al. 2002; Menzies et al. 2002; Raimondi et al. 2006; Xu et al. 2004).

Several lines of evidence further indicate that these mitochondrial morphology changes are tightly associated with mitochondrial dysfunctions. Changes in the activity of the different complexes of the electron transport chain have been described in tissues obtained from ALS patients, and in cell and animal disease models. Although some of these studies have produced mixed and somewhat contradictory results, the most consistent abnormality in mitochondrial respiratory function has been associated with reduced complex I and IV activity (Browne et al. 1998; Kirkinezos et al. 2005; Mattiazzi et al. 2002; Menzies et al. 2002; Rizzardini et al. 2006; Son et al. 2008). In motor neurons of mutant $\mathrm{SOD} 1^{\mathrm{G} 93 \mathrm{~A}}$ mice a reduction in activity of complex I was observed before disease onset and progressing to inhibition of complex IV at later stages (Jung et al. 2002). In neuroblastoma cells overexpressing mutant SOD1 ${ }^{\mathrm{G} 37 \mathrm{R}}$, we observed a decreased activity of complex I in mitochondrial fractions (Coussee et al. 2011). This reduction was not related to a lower expression level of complex I.

The maintenance of the mitochondrial membrane potential is reliant on the activity of the different complexes of the electron transport chain. Consistent with this, mitochondrial depolarization has been observed in neuroblastoma cells expressing mutant SOD1 ${ }^{\mathrm{G} 93 \mathrm{~A}}$ (Carri et al. 1997) or SOD $1^{\mathrm{G} 37 \mathrm{R}}$ (Coussee et al. 2011) and in motor neurons from mutant SOD1 ${ }^{\text {G93A }}$ mice (Kruman et al. 1999). Stimulationinduced mitochondrial membrane depolarizations in motor terminals of G93A and G85R transgenic mice were significantly enhanced and increased the likelihood of mitochondrial permeability transition pore opening during mitochondrial $\mathrm{Ca}^{2+}$ uptake (Nguyen et al. 2011; Nguyen et al. 2009).

Another set of observations, providing further evidence for mitochondrial dysfunctions in the pathogenesis of familial ALS include impaired ATP synthesis and reduced mitochon- drial $\mathrm{Ca}^{2+}$ buffering in cells expressing a number of different SOD1 mutations. For example, ATP generation was markedly decreased in neuronal cells of mutant $\mathrm{SOD} 1^{\mathrm{G} 93 \mathrm{~A}}$ mice (Browne et al. 2006; Mattiazzi et al. 2002). Cytosolic ATP levels were significantly reduced in neuroblastoma cells expressing mutant SOD $1^{\mathrm{G} 37 \mathrm{R}}$ (Coussee et al. 2011) and decreased more rapidly and to a greater extent in rotenonetreated SOD $1^{\mathrm{G} 93 \mathrm{~A}}$ neuronal cells (Rizzardini et al. 2006). Impairment of intracellular $\mathrm{Ca}^{2+}$ homeostasis has been reported in cells expressing mutant $\mathrm{SOD} 1^{\mathrm{G} 93 \mathrm{~A}}$ or $\mathrm{SOD} 1^{\mathrm{G} 37 \mathrm{R}}$ (Carri et al. 1997; Coussee et al. 2011; Tradewell et al. 2011) and in motor neurons from mutant SOD $1^{\mathrm{G} 93 \mathrm{~A}}$ transgenic mice (Jaiswal and Keller 2009; Jaiswal et al. 2009; Kruman et al. 1999). Also isolated mitochondria from transgenic mutant $\mathrm{SOD} 1^{\mathrm{G} 93 \mathrm{~A}}$ and $\mathrm{SOD} 1^{\mathrm{G} 85 \mathrm{R}}$ mice showed a significant decrease in $\mathrm{Ca}^{2+}$ loading capacity (Damiano et al. 2006; Nguyen et al. 2009; Vila et al. 2003). ATP deficit and $\mathrm{Ca}^{2+}$ dysregulation may arise secondary to mutant SOD1-induced impairment of oxidative phosphorylation, or as a direct consequence of mutant SOD1 impeding on mitochondrial transport of ions and metabolites.

Finally, numerous studies have found evidence of increased oxidative and/or nitrosative stress in ALS pathogenesis. Transgenic mouse models of ALS expressing mutant human SOD1 support human studies showing increased oxidative damage to mitochondrial proteins, lipids and DNA (reviewed in Barber and Shaw 2010). This has been explained by excessive dismutase activity of mutant SOD1 (Goldsteins et al. 2008; Wiedau-Pazos et al. 1996), increased levels of ROS produced by mitochondria following inhibition of complex I (Kruman et al. 1999; Mattiazzi et al. 2002; Murphy 2009; Zimmerman et al. 2007), or increased NADPH oxidase (NOX) activity through mutant SOD1 interacting with Rac1, a NOX regulator (reviewed in Boillee and Cleveland 2008). It should be noted, however, that recent data indicate that overexpression of mutant $\mathrm{SOD} 1^{\mathrm{G} 93 \mathrm{~A}}$ in yeast cells actually provided increased protection against respiration-derived ROS (Kloppel et al. 2010).

Despite the clear evidence that mutant SOD1 induces a fundamental impairment in energy metabolism mechanisms, $\mathrm{Ca}^{2+}$ homeostasis and ROS handling, the exact cause and effect remain unclear. A number of potential scenarios exist. Of particular interest is the observation that mutant SOD1 preferentially accumulates at the cytoplasmic face of the outer membrane and in the intermembrane space of mitochondria (Cozzolino et al. 2009; Ferri et al. 2006; Higgins et al. 2003; Sotelo-Silveira et al. 2009). Therefore, it is possible that an aberrant association between mutant SOD1 and mitochondrial proteins may lead to impaired electron transport chain functioning, shortage of ATP, increased ROS formation and $\mathrm{Ca}^{2+}$ dysregulation. 


\section{Mutant SOD1 may affect ER-mitochondrial coupling}

One way how mislocalized mutant SOD1 could affect mitochondrial functions is through direct interaction with outer mitochondrial membrane proteins. Mutant SOD1 has been shown to associate with Lysyl-tRNA synthetase (Kawamata et al. 2008), an enzyme required for mitDNAencoded protein translation, members of the Bcl-2 family of proteins (Arbel and Shoshan-Barmatz 2010) and the voltage-dependent anion channel VDAC1 (Israelson et al. 2010). The binding of mutant SOD1 to VDAC1 deserves further attention. VDAC1 is a multifunctional mitochondrial protein involved in the transport of ions and small molecules including $\mathrm{Ca}^{2+}$, ATP/ADP and NADH, across the mitochondrial outer membrane (reviewed in Colombini 2004; Pedersen 2008; Shoshan-Barmatz and Ben-Hail 2011; Shoshan-Barmatz et al. 2010). Changes in the transport rate of these ions and molecules will affect mitochondrial and cellular metabolism, positioning VDAC1 at a key position in the cellular energy metabolism. VDAC1 has also been found in ER membrane fractions, notably at contact sites between mitochondria and ER, where it may catalyze the uptake of ATP (Shoshan-Barmatz and Israelson 2005). In addition to its key role in energy metabolism, VDAC1 also binds to proand anti-apoptotic proteins of the Bcl-2 family, is an essential component of the permeability transition pore and has therefore been proposed to be a key player in mitochondriamediated apoptosis (reviewed in Shoshan-Barmatz and BenHail 2011; Shoshan-Barmatz et al. 2010). Furthermore, VDAC1 interacts with several other mitochondrial and cytosolic proteins and recent evidence indicates that it may be part of the physical link between mitochondria and the ER

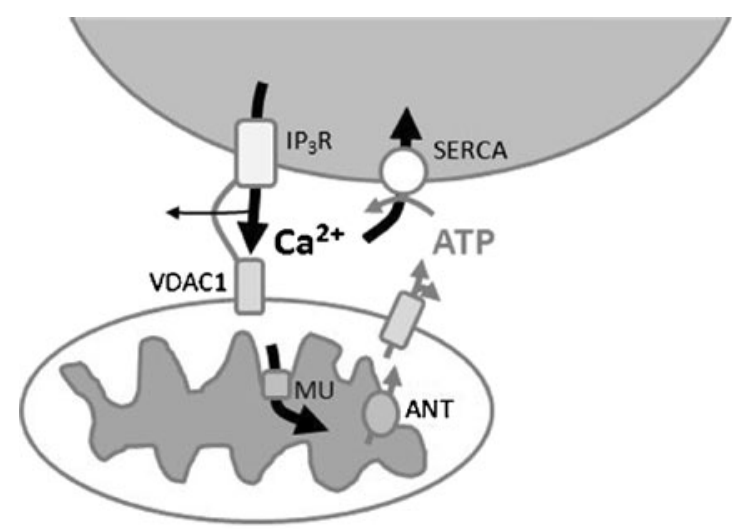

Fig. 1 Simplified model for altered mitochondrial $\mathrm{Ca}^{2+}$ uptake and ATP production in mutant SOD1 cells. Binding of mutant SOD1 (mSOD1) to VDAC1 results in uncoupling of $\mathrm{ER} /$ mitochondrial network leading to diminished mitochondrial $\mathrm{Ca}^{2+}$ uptake, increased
$\mathrm{Ca}^{2+}$-release channel inositol 1,4,5-trisphosphate receptor $\left(\mathrm{IP}_{3} \mathrm{R}\right)$ (Szabadkai et al. 2006). This tight coupling between ER and mitochondria through $\mathrm{IP}_{3} \mathrm{R}-\mathrm{VDAC} 1$ associations not only allows VDAC1-mediated $\mathrm{Ca}^{2+}$ fluxes to the intermembrane space from the high $\left[\mathrm{Ca}^{2+}\right]$ microdomain created by activation of $\mathrm{IP}_{3} \mathrm{Rs}$ but also provides high [ATP] microdomains required for subsequent SERCA-mediated $\mathrm{Ca}^{2+}$ reuptake into the ER. It thus seems obvious that even small changes in the number or distance of these physical contacts between mitochondria and ER may have profound effects on mitochondrial and cellular functions. A decrease in the number of physical contacts between mitochondria and ER or an increase in their distance would diminish mitochondrial $\mathrm{Ca}^{2+}$ uptake induced by $\mathrm{IP}_{3}$-mediated $\mathrm{Ca}^{2+}$ release. Since mitochondrial oxidative phosphorylation is stimulated at different levels (three dehydrogenases of the Krebs cycle and the $\mathrm{F}_{1} \mathrm{~F}_{0}$ ATP synthase) by $\mathrm{Ca}^{2+}$ (Jouaville et al. 1999), reduced mitochondrial $\mathrm{Ca}^{2+}$ uptake would impede ATP production. For the same reasons, ER-mitochondrial uncoupling would limit the generation of [ATP] hot spots. In addition, the recent finding that mutant SOD1 binding to VDAC1 reduces VDAC1-mediated ADP transport across the outer mitochondrial membrane (Israelson et al. 2010) will further limit ATP synthesis. In all these cases, ATP generation may thus be seriously hampered that it actually falls short of cytosolic ATP demand during on-going cellular activity. Since VDAC1 plays a central role in cellular metabolism and serves as a mitochondrial-binding site for other proteins, including mutant SOD1 and $\mathrm{IP}_{3} \mathrm{Rs}$, an appealing hypothesis is that this aberrant interaction of mutant SOD1 with VDAC1 not only impairs VDAC1mediated transport across the mitochondrial outer membrane

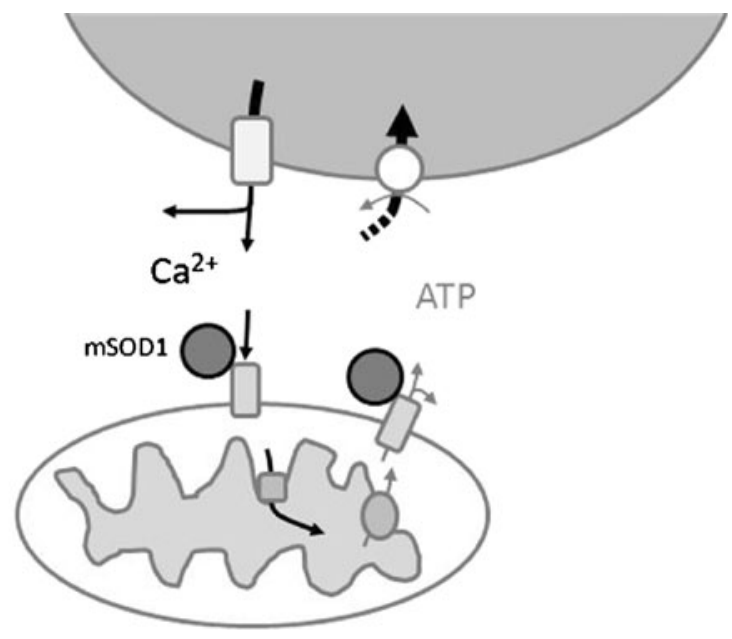

cytosolic $\mathrm{Ca}^{2+}$ transient and lower ATP availability. Dark grey level corresponds to high $\mathrm{Ca}^{2+}$ content; thick black arrows reflect high $\mathrm{Ca}^{2+}$ flux; thick grey arrows reflect high ATP flux. MU mitochondrial uniporter; ANT adenine nucleotide transporter 
but also destabilizes VDAC1 binding to $\mathrm{IP}_{3} \mathrm{Rs}$. This leads to a reduction of the number of VDAC1 proteins available for $\mathrm{IP}_{3} \mathrm{R}$ coupling and hence impairing the privileged communication between mitochondria and ER (Fig. 1).

Consistent with this hypothesis, our own findings in N2a neuroblastoma cells overexpressing mutant SOD $1^{\mathrm{G} 37 \mathrm{R}}$ showed decreased $\mathrm{IP}_{3}$-induced mitochondrial $\mathrm{Ca}^{2+}$ uptake in intact cells compared to parental cells (Coussee et al. 2011). $\mathrm{IP}_{3}$-induced mitochondrial $\mathrm{Ca}^{2+}$ uptake was not affected in cells overexpressing wild-type SOD1. $\mathrm{Ca}^{2+}$ induced mitochondrial $\mathrm{Ca}^{2+}$ uptake in permeabilized cells, which does not rely on $\mathrm{ER}^{\mathrm{Ca}^{2+}}$ release or the intimate coupling between mitochondria and ER, was not affected in mutant $\mathrm{SOD} 1^{\mathrm{G} 37 \mathrm{R}}$ cells. This finding is also consistent with the observation that mutant SOD1 does not affect VDAC1mediated $\mathrm{Ca}^{2+}$ transfer (Israelson et al. 2010). Cytosolic ATP levels were also significantly decreased in mutant SOD $1^{\mathrm{G} 37 \mathrm{R}}$ cells resulting in compromised ER $\mathrm{Ca}^{2+}$ uptake in intact cells while ER $\mathrm{Ca}^{2+}$ uptake in permeabilized cells provided with sufficient amounts of ATP was not affected. Our finding that complex I activity is significantly impaired in mutant $\mathrm{SOD} 1^{\mathrm{G} 37 \mathrm{R}}$ cells may reflect reduced VDAC1 permeability for metabolites necessary for respiration. Finally, using confocal microscopy, we compared the distribution of the ER marker Dsred with that of the mitochondrial marker mit-GFP. A quantitative analysis of colocalization between the two signals revealed a lower Mander's coefficient (Mc) in mutant SOD ${ }^{\mathrm{G} 37 \mathrm{R}}$ cells (Mc of 0.64) compared to wild-type SOD1 cells (Mc of 0.56) (unpublished preliminary data). These results suggest a loss of coupling between mitochondria and ER in mutant SOD $1^{\mathrm{G} 37 \mathrm{R}}$ cells. Further studies will be needed to corroborate these findings by quantifying $\mathrm{Ca}^{2+}$ hot spots or assessing VDAC1 localization at ER-mitochondria contact sites in mutant $\mathrm{SOD} 1^{\mathrm{G} 37 \mathrm{R}}$ cells.

Because mitochondrial $\mathrm{Ca}^{2+}$ uptake during $\mathrm{IP}_{3}$-induced $\mathrm{Ca}^{2+}$ release was significantly reduced in mutant $\mathrm{SOD} 1^{\mathrm{G} 37 \mathrm{R}}$ cells, $\mathrm{IP}_{3}$-induced $\mathrm{Ca}^{2+}$ release led to significant larger cytosolic $\mathrm{Ca}^{2+}$ signals. Since mutant SOD ${ }^{\mathrm{G} 37 \mathrm{R}}$ expression had no major effects on the viability of N2a neuroblastoma cells, the extrapolation of these findings to motor neuron degeneration appears trivial. However, unlike many other cell types, motor neurons display low cytosolic $\mathrm{Ca}^{2+}$ buffering (Grosskreutz et al. 2007; von Lewinski et al. 2008) and heavily rely on oxidative phosphorylation during on-going rhythmic activity. It therefore becomes apparent that cytosolic $\mathrm{Ca}^{2+}$ overloading and ATP shortage in motor neurons carrying SOD1 mutations are predominant and pose a sustained metabolic stress on mitochondria, accelerating cellular ageing and ultimately lowering the threshold for apoptosis.

In summary, the aberrant interaction of mutant SOD1 with VDAC1 may impair VDAC1-mediated transport and ER-mitochondria coupling resulting in decreased mitochon- drial $\mathrm{Ca}^{2+}$ uptake and ATP production. This $\mathrm{Ca}^{2+}$ dysregulation and energetic deficit may represent the starting point for a vicious circle leading to motor neuron degeneration in familial ALS.

Open Access This article is distributed under the terms of the Creative Commons Attribution Noncommercial License which permits any noncommercial use, distribution, and reproduction in any medium, provided the original author(s) and source are credited.

\section{References}

Arbel N, Shoshan-Barmatz V (2010) Voltage-dependent anion channel 1-based peptides interact with $\mathrm{Bcl}-2$ to prevent antiapoptotic activity. J Biol Chem 285:6053-6062

Barber SC, Shaw PJ (2010) Oxidative stress in ALS: key role in motor neuron injury and therapeutic target. Free Radic Biol Med 48:629-641

Bendotti C, Calvaresi N, Chiveri L, Prelle A, Moggio M, Braga M, Silani V, De Biasi S (2001) Early vacuolization and mitochondrial damage in motor neurons of FALS mice are not associated with apoptosis or with changes in cytochrome oxidase histochemical reactivity. J Neurol Sci 191:25-33

Boillee S, Cleveland DW (2008) Revisiting oxidative damage in ALS: microglia, Nox, and mutant SOD1. J Clin Invest 118:474-478

Boillee S, Vande Velde C, Cleveland DW (2006) ALS: a disease of motor neurons and their nonneuronal neighbors. Neuron 52:39-59

Borchelt DR, Lee MK, Slunt HS, Guarnieri M, Xu ZS, Wong PC, Brown RH Jr, Price DL, Sisodia SS, Cleveland DW (1994) Superoxide dismutase 1 with mutations linked to familial amyotrophic lateral sclerosis possesses significant activity. Proc Natl Acad Sci U S A 91:8292-8296

Bowling AC, Barkowski EE, McKenna-Yasek D, Sapp P, Horvitz HR, Beal MF, Brown RH Jr (1995) Superoxide dismutase concentration and activity in familial amyotrophic lateral sclerosis. J Neurochem 64:2366-2369

Browne SE, Bowling AC, Baik MJ, Gurney M, Brown RH Jr, Beal MF (1998) Metabolic dysfunction in familial, but not sporadic, amyotrophic lateral sclerosis. J Neurochem 71:281-287

Browne SE, Yang L, DiMauro JP, Fuller SW, Licata SC, Beal MF (2006) Bioenergetic abnormalities in discrete cerebral motor pathways presage spinal cord pathology in the G93A SOD1 mouse model of ALS. Neurobiol Dis 22:599-610

Carri MT, Ferri A, Battistoni A, Famhy L, Gabbianelli R, Poccia F, Rotilio G (1997) Expression of a $\mathrm{Cu}, \mathrm{Zn}$ superoxide dismutase typical of familial amyotrophic lateral sclerosis induces mitochondrial alteration and increase of cytosolic $\mathrm{Ca}^{2+}$ concentration in transfected neuroblastoma SH-SY5Y cells. FEBS Lett 414:365-368

Cleveland DW, Rothstein JD (2001) From Charcot to Lou Gehrig: deciphering selective motor neuron death in ALS. Nat Rev Neurosci 2:806-819

Colombini M (2004) VDAC: the channel at the interface between mitochondria and the cytosol. Mol Cell Biochem 256-257:107-115

Coussee E, De Smet P, Bogaert E, Elens I, Van Damme P, Willems P, Koopman W, Van Den Bosch L, Callewaert G (2011) G37R SOD1 mutant alters mitochondrial complex I activity, $\mathrm{Ca}^{2+}$ uptake and ATP production. Cell Calcium 49:217-225

Cozzolino M, Pesaresi MG, Amori I, Crosio C, Ferri A, Nencini M, Carri MT (2009) Oligomerization of mutant SOD1 in mitochondria of motoneuronal cells drives mitochondrial damage and cell toxicity. Antioxid Redox Signal 11:1547-1558 
Damiano M, Starkov AA, Petri S, Kipiani K, Kiaei M, Mattiazzi M, Flint Beal M, Manfredi G (2006) Neural mitochondrial $\mathrm{Ca}^{2+}$ capacity impairment precedes the onset of motor symptoms in $\mathrm{G} 93 \mathrm{~A} \mathrm{Cu} / \mathrm{Zn}$ superoxide dismutase mutant mice. J Neurochem 96:1349-1361

Duffy LM, Chapman AL, Shaw PJ, Grierson AJ (2011) Review: The role of mitochondria in the pathogenesis of amyotrophic lateral sclerosis. Neuropathol Appl Neurobiol 37:336-352

Ferri A, Cozzolino M, Crosio C, Nencini M, Casciati A, Gralla EB, Rotilio G, Valentine JS, Carri MT (2006) Familial ALS-superoxide dismutases associate with mitochondria and shift their redox potentials. Proc Natl Acad Sci U S A 103:13860-13865

Goldsteins G, Keksa-Goldsteine V, Ahtoniemi T, Jaronen M, Arens E, Akerman K, Chan PH, Koistinaho J (2008) Deleterious role of superoxide dismutase in the mitochondrial intermembrane space. J Biol Chem 283:8446-8452

Grosskreutz J, Haastert K, Dewil M, Van Damme P, Callewaert G, Robberecht W, Dengler R, Van Den Bosch L (2007) Role of mitochondria in kainate-induced fast $\mathrm{Ca}^{2+}$ transients in cultured spinal motor neurons. Cell Calcium 42:59-69

Grosskreutz J, Van Den Bosch L, Keller BU (2010) Calcium dysregulation in amyotrophic lateral sclerosis. Cell Calcium 47:165-174

Hervias I, Beal MF, Manfredi G (2006) Mitochondrial dysfunction and amyotrophic lateral sclerosis. Muscle Nerve 33:598-608

Higgins CM, Jung C, Xu Z (2003) ALS-associated mutant SOD1G93A causes mitochondrial vacuolation by expansion of the intermembrane space and by involvement of SOD1 aggregation and peroxisomes. BMC Neurosci 4:16

Israelson A, Arbel N, Da Cruz S, Ilieva H, Yamanaka K, ShoshanBarmatz V, Cleveland DW (2010) Misfolded mutant SOD1 directly inhibits VDAC1 conductance in a mouse model of inherited ALS. Neuron 67:575-587

Jaarsma D, Rognoni F, van Duijn W, Verspaget HW, Haasdijk ED, Holstege JC (2001) CuZn superoxide dismutase (SOD1) accumulates in vacuolated mitochondria in transgenic mice expressing amyotrophic lateral sclerosis-linked SOD1 mutations. Acta Neuropathol 102:293-305

Jaiswal MK, Keller BU (2009) Cu/Zn superoxide dismutase typical for familial amyotrophic lateral sclerosis increases the vulnerability of mitochondria and perturbs $\mathrm{Ca}^{2+}$ homeostasis in SOD1G93A mice. Mol Pharmacol 75:478-489

Jaiswal MK, Zech WD, Goos M, Leutbecher C, Ferri A, Zippelius A, Carri MT, Nau R, Keller BU (2009) Impairment of mitochondrial calcium handling in a mtSOD1 cell culture model of motoneuron disease. BMC Neurosci 10:64

Jouaville LS, Pinton P, Bastianutto C, Rutter GA, Rizzuto R (1999) Regulation of mitochondrial ATP synthesis by calcium: evidence for a long-term metabolic priming. Proc Natl Acad Sci U S A 96:13807-13812

Jung C, Higgins CM, Xu Z (2002) Mitochondrial electron transport chain complex dysfunction in a transgenic mouse model for amyotrophic lateral sclerosis. J Neurochem 83:535-545

Kawamata H, Magrane J, Kunst C, King MP, Manfredi G (2008) Lysyl-tRNA synthetase is a target for mutant SOD1 toxicity in mitochondria. J Biol Chem 283:28321-28328

Kirkinezos IG, Bacman SR, Hernandez D, Oca-Cossio J, Arias LJ, Perez-Pinzon MA, Bradley WG, Moraes CT (2005) Cytochrome $\mathrm{c}$ association with the inner mitochondrial membrane is impaired in the CNS of G93A-SOD1 mice. J Neurosci 25:164-172

Kloppel C, Michels C, Zimmer J, Herrmann JM, Riemer J (2010) In yeast redistribution of Sod1 to the mitochondrial intermembrane space provides protection against respiration derived oxidative stress. Biochem Biophys Res Commun 403:114-119

Kruman II, Pedersen WA, Springer JE, Mattson MP (1999) ALSlinked $\mathrm{Cu} / \mathrm{Zn}$-SOD mutation increases vulnerability of motor neurons to excitotoxicity by a mechanism involving increased oxidative stress and perturbed calcium homeostasis. Exp Neurol 160:28-39

Manfredi G, Xu Z (2005) Mitochondrial dysfunction and its role in motor neuron degeneration in ALS. Mitochondrion 5:77-87

Mattiazzi M, D'Aurelio M, Gajewski CD, Martushova K, Kiaei M, Beal MF, Manfredi G (2002) Mutated Human SOD1 Causes Dysfunction of Oxidative Phosphorylation in Mitochondria of Transgenic Mice. J Biol Chem 277:29626-29633

Menzies FM, Cookson MR, Taylor RW, Turnbull DM, ChrzanowskaLightowlers ZM, Dong L, Figlewicz DA, Shaw PJ (2002) Mitochondrial dysfunction in a cell culture model of familial amyotrophic lateral sclerosis. Brain 125:1522-1533

Murphy MP (2009) How mitochondria produce reactive oxygen species. Biochem J 417:1-13

Nguyen KT, Garcia-Chacon LE, Barrett JN, Barrett EF, David G (2009) The Psi(m) depolarization that accompanies mitochondrial $\mathrm{Ca}^{2+}$ uptake is greater in mutant SOD1 than in wild-type mouse motor terminals. Proc Natl Acad Sci U S A 106:2007-2011

Nguyen KT, Barrett JN, Garcia-Chacon L, David G, Barrett EF (2011) Repetitive nerve stimulation transiently opens the mitochondrial permeability transition pore in motor nerve terminals of symptomatic mutant SOD1 mice. Neurobiol Dis 42:381-390

Pasinelli P, Brown RH (2006) Molecular biology of amyotrophic lateral sclerosis: insights from genetics. Nat Rev Neurosci 7:710-723

Pedersen PL (2008) Voltage dependent anion channels (VDACs): a brief introduction with a focus on the outer mitochondrial compartment's roles together with hexokinase-2 in the "Warburg effect" in cancer. J Bioenerg Biomembr 40:123-126

Raimondi A, Mangolini A, Rizzardini M, Tartari S, Massari S, Bendotti C, Francolini M, Borgese N, Cantoni L, Pietrini G (2006) Cell culture models to investigate the selective vulnerability of motoneuronal mitochondria to familial ALS-linked G93ASOD1. Eur J Neurosci 24:387-399

Reaume AG, Elliott JL, Hoffman EK, Kowall NW, Ferrante RJ, Siwek DF, Wilcox HM, Flood DG, Beal MF, Brown RH Jr et al (1996) Motor neurons in $\mathrm{Cu} / \mathrm{Zn}$ superoxide dismutase-deficient mice develop normally but exhibit enhanced cell death after axonal injury. Nat Genet 13:43-47

Rizzardini M, Lupi M, Mangolini A, Babetto E, Ubezio P, Cantoni L (2006) Neurodegeneration induced by complex I inhibition in a cellular model of familial amyotrophic lateral sclerosis. Brain Res Bull 69:465-474

Rosen DR, Siddique T, Patterson D, Figlewicz DA, Sapp P, Hentati A, Donaldson D, Goto J, O'Regan JP, Deng HX et al (1993) Mutations in $\mathrm{Cu} / \mathrm{Zn}$ superoxide dismutase gene are associated with familial amyotrophic lateral sclerosis. Nature 362:59-62

Sasaki S, Iwata M (1996) Ultrastructural study of synapses in the anterior horn neurons of patients with amyotrophic lateral sclerosis. Neurosci Lett 204:53-56

Shoshan-Barmatz V, Ben-Hail D (2011) VDAC, a multi-functional mitochondrial protein as a pharmacological target. Mitochondrion

Shoshan-Barmatz V, Israelson A (2005) The voltage-dependent anion channel in endoplasmic/sarcoplasmic reticulum: characterization, modulation and possible function. J Membr Biol 204:57-66

Shoshan-Barmatz V, De Pinto V, Zweckstetter M, Raviv Z, Keinan N, Arbel N (2010) VDAC, a multi-functional mitochondrial protein regulating cell life and death. Mol Aspects Med 31:227-285

Siklos L, Engelhardt J, Harati Y, Smith RG, Joo F, Appel SH (1996) Ultrastructural evidence for altered calcium in motor nerve terminals in amyotropic lateral sclerosis. Ann Neurol 39:203-216

Son M, Leary SC, Romain N, Pierrel F, Winge DR, Haller RG, Elliott JL (2008) Isolated cytochrome c oxidase deficiency in G93A SOD1 mice overexpressing CCS protein. J Biol Chem 283:12267-12275 
Sotelo-Silveira JR, Lepanto P, Elizondo V, Horjales S, Palacios F, Martinez-Palma L, Marin M, Beckman JS, Barbeito L (2009) Axonal mitochondrial clusters containing mutant SOD1 in transgenic models of ALS. Antioxid Redox Signal 11:1535-1545

Szabadkai G, Bianchi K, Varnai P, De Stefani D, Wieckowski MR, Cavagna D, Nagy AI, Balla T, Rizzuto R (2006) Chaperonemediated coupling of endoplasmic reticulum and mitochondrial $\mathrm{Ca}^{2+}$ channels. J Cell Biol 175:901-911

Tradewell ML, Cooper LA, Minotti S, Durham HD (2011) Calcium dysregulation, mitochondrial pathology and protein aggregation in a culture model of amyotrophic lateral sclerosis: mechanistic relationship and differential sensitivity to intervention. Neurobiol Dis 42:265-275

Turner BJ, Talbot K (2008) Transgenics, toxicity and therapeutics in rodent models of mutant SOD1-mediated familial ALS. Prog Neurobiol 85:94-134
Vila L, Barrett EF, Barrett JN (2003) Stimulation-induced mitochondrial $\left[\mathrm{Ca}^{2+}\right]$ elevations in mouse motor terminals: comparison of wild-type with SOD1-G93A. J Physiol 549:719-728

von Lewinski F, Fuchs J, Vanselow BK, Keller BU (2008) Low $\mathrm{Ca}^{2+}$ buffering in hypoglossal motoneurons of mutant SOD1 (G93A) mice. Neurosci Lett 445:224-228

Wiedau-Pazos M, Goto JJ, Rabizadeh S, Gralla EB, Roe JA, Lee MK, Valentine JS, Bredesen DE (1996) Altered reactivity of superoxide dismutase in familial amyotrophic lateral sclerosis. Science 271:515-518

Xu Z, Jung C, Higgins C, Levine J, Kong J (2004) Mitochondrial degeneration in amyotrophic lateral sclerosis. J Bioenerg Biomembr 36:395-399

Zimmerman MC, Oberley LW, Flanagan SW (2007) Mutant SOD1induced neuronal toxicity is mediated by increased mitochondrial superoxide levels. J Neurochem 102:609-618 